\title{
Coupled dynamic analysis on the drive-off of deepwater platform/riser system
}

\author{
Xiuquan Liu*, Guoming Chen**, Jingqi Ji***, Jingjie Fu**** \\ *China University of Petroleum, Qingdao 266580, China, E-mail: lxqmcae@163.com \\ **China University of Petroleum, Qingdao 266580, China, E-mail: offshore@126.com \\ ***China University of Petroleum, Qingdao 266580, China, E-mail: $1210457611 @$ qq.com \\ ****China University of Petroleum, Qingdao 266580, China, E-mail: fujingjie123@163.com \\ cross $^{\text {ref }}$ http://dx.doi.org/10.5755/j01.mech.23.2.13780
}

\section{Introduction}

Dynamic positioning (DP) is a station keeping technique consisting of on-board thrusters that are automatically controlled to maintain a floating structure's position. The DP system mainly consists of power system, thruster, control system, position reference system, etc. Any component failure can result in the loss of position. There exist two main scenarios for the loss of position during a DP-operation, namely drive-off and drift-off. The drive-off is a powered move away from the desired platform position. The drift-off is a loss of power that causes the platform to move off location in the direction of the prevailing environment. During the drive-off and drift-off motion of platform, the platform pulls the top of riser system away from subsea wellhead in the horizontal direction. The lower marine riser package (LMRP) needs to be disconnected timely, or the serious accidents may happen, such as riser broken, subsea wellhead damage and even well blowout [1-4]. Basically, it is more likely that damage occurs in a drive-off situation than in a drift-off situation [5]. So, the accurate prediction of the drive-off dynamics of deepwater platform and riser system is crucial.

The dynamics of deepwater DP platform has been widely studied $[6,7]$. Most studies focus on the mathematical modeling and DP control of deepwater platform when DP system is in a good condition. Specific to the dynamic analysis on the drive-off of deepwater platform system when DP system is failed, Ambrose et al. [8] pointed out that typical limits governing the disconnect point of riser during platform drive-off or drift-off were slip joint, tensioner stroke, upper and lower riser angle, bending moments in wellhead and structural casing. Bhalla et al. [9] developed a procedure to predict the vessel trajectory in a drive-off or drift-off event. Commercial software ABAQUS and in-house software DERP are used to develop the riser response to the vessel drive-off and drift-off individually. Gjerde et al. [10] presented an alternative probabilistic methodology to determine the red limit based on the probabilistic modeling of position loss scenarios. However, the coupled dynamic analysis method on the drive-off of deepwater platform/riser system has not been reported. And the coupling effect between deepwater platform and riser has not been studied so far.

The main emphasis of the work is set to the coupled dynamic analysis on the drive-off of deepwater platform/riser system. The paper is structured as follows: Section 2 presents dynamic analysis models of platform and riser system, and gives the coupled drive-off analysis pro- cess. Section 3 analyzes a case to demonstrate the application of the coupled analysis method. Section 4 summarizes the paper.

\section{Methodology}

\subsection{Deepwater platform/riser system}

The deepwater platform/riser system includes platform, riser, upper flex joint (UFJ), lower flex joint (LFJ), LMRP, blowout preventer (BOP), subsea wellhead, conductor, etc, as shown in Fig. 1. The top end of riser is hanged on drilling platform via tensioner, and the bottom end of riser is connected to LMRP, BOP, subsea wellhead and conductor [11]. The deepwater platform/riser system suffers ocean environment loads of thruster, wind, wave, current and soil resistance. Besides, the deepwater platform and riser also interact on each other. For example, the deepwater platform drives off due to the fault of DP system, and the platform will pull the top of riser system away from subsea wellhead in the horizontal direction. In return, the riser system will generate a reaction force to change the drive-off motion of platform. Thus, the load of deepwater platform/riser system is complex and interactional. The dynamic analysis model for the drive-off of deepwater platform and riser should be established respectively and analyzed iteratively.

\subsection{Drive-off analysis equations of platform}

The loads of deepwater platform have close relationship with its local coordinate and motion state. The global reference frame and body-fixed reference frame are established respectively to describe the motion state of platform better, as shown in Fig. 2. $X O Y$ is global reference frame, and $X_{b} O_{b} Y_{b}$ is body-fixed reference frame. The transformation of platform velocity between global reference frame and body-fixed reference frame is given by [12]:

$$
\dot{\boldsymbol{\eta}}=\boldsymbol{R}(\psi) \boldsymbol{v}=\left[\begin{array}{ccc}
\cos \psi & -\sin \psi & 0 \\
\sin \psi & \cos \psi & 0 \\
0 & 0 & 1
\end{array}\right] \boldsymbol{v}
$$

where $\boldsymbol{\eta}=\left[\begin{array}{lll}x & y & \psi\end{array}\right]^{T}$ is platform position and heading in the global reference frame, $v=[u v r]^{T}$ is the surge, sway and yaw velocity of platform in body-fixed reference frame, and $\boldsymbol{R}(\psi)$ is the transformation matrix between 
global reference frame and body-fixed reference frame.

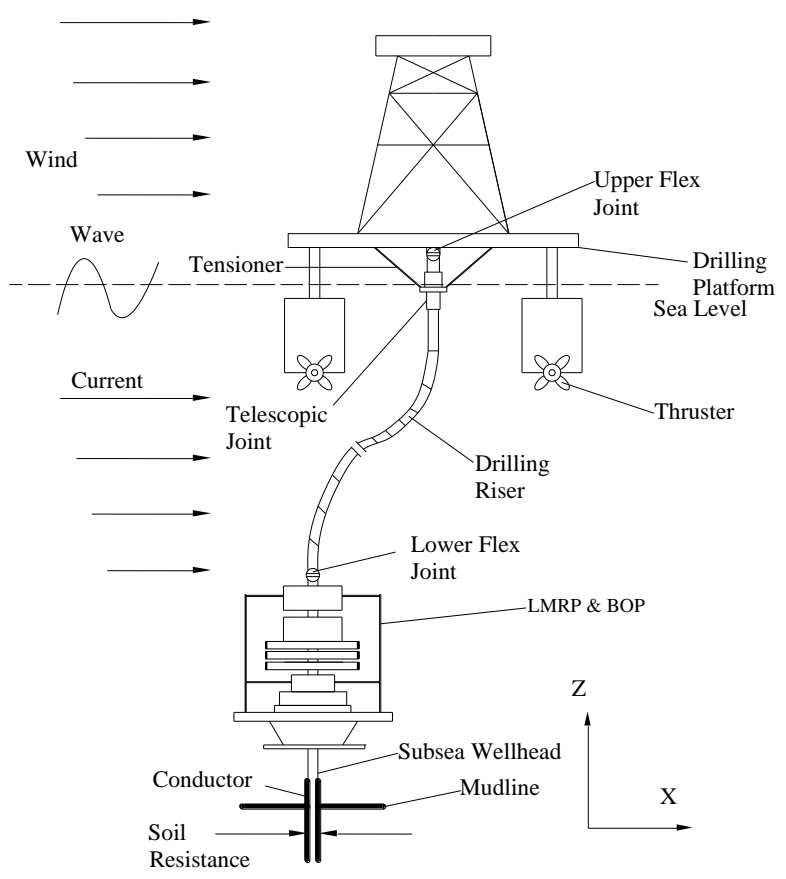

Fig. 1 Deepwater platform/riser system

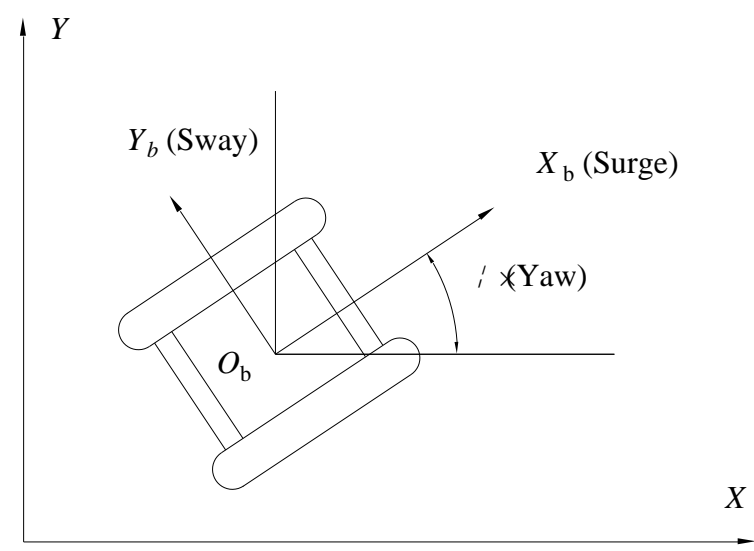

Fig. 2 Reference frames

The deepwater platform drives off in surge, sway and yaw under the loads of thruster, wind, current, second order wave force and riser force. The nonlinear body-fixed equations of the drive-off motion are written:

$$
\boldsymbol{M} \dot{\boldsymbol{v}}+\boldsymbol{C}_{R B} \boldsymbol{v}=\boldsymbol{\tau}_{\text {curr }}+\boldsymbol{\tau}_{\text {wind }}+\boldsymbol{\tau}_{\text {wave }}+\boldsymbol{\tau}_{\text {thruster }}+\boldsymbol{\tau}_{\text {riser }},
$$

where $\boldsymbol{M}$ is mass matrix of platform; $\boldsymbol{C}_{R B}$ is skewsymmetric Coriolis and centripetal matrix, and $\boldsymbol{\tau}_{\text {curr }}, \boldsymbol{\tau}_{\text {wave }}$, $\boldsymbol{\tau}_{\text {wind }}, \boldsymbol{\tau}_{\text {thruster }}, \boldsymbol{\tau}_{\text {riser }}$ are vectors of current load, second order wave load, wind load, thruster force and riser force, respectively.

The mass matrix of platform including platform mass and added mass is defined as:

$$
\boldsymbol{M}=\left[\begin{array}{ccc}
m+X_{\dot{u}} & 0 & 0 \\
0 & m+Y_{\dot{v}} & Y_{\dot{r}} \\
0 & N_{\dot{v}} & I_{z}+N_{\dot{r}}
\end{array}\right],
$$

where $m$ is the platform mass; $I_{\mathrm{Z}}$ is the moment of inertia of platform about the $z$-axis. The terms $X_{\dot{u}}, Y_{\dot{v}}, N_{\dot{r}}$ are the zero-frequency added mass in surge, sway, and yaw. $Y_{\dot{r}}$ is added mass of platform in the surge due to a unit yaw acceleration. $N_{\dot{v}}$ is added moment of inertia of platform about $z$ axis due to a unit acceleration of the platform in sway.

The skew-symmetric Coriolis and centripetal matrix of the platform can be formulated as:

$$
\boldsymbol{C}_{\mathrm{RB}}=\left[\begin{array}{ccc}
0 & 0 & -m v \\
0 & 0 & m u \\
m v & -m u & 0
\end{array}\right],
$$

The loads of current and wind are in quadratic relationship to the relative velocity between platform and current or wind. The current and wind load vectors in surge, sway and yaw are formulated as:

$$
\begin{gathered}
\tau_{c}=\left\{\begin{array}{l}
C_{c x}\left(\beta_{c}\right) u_{c}{ }^{2} ; \\
C_{c y}\left(\beta_{c}\right) u_{c}{ }^{2} ;, \\
C_{c z}\left(\beta_{c}\right) u_{c}{ }^{2} ;
\end{array}\right. \\
\tau_{w i n d}=\left\{\begin{array}{l}
C_{w d x}\left(\beta_{w d}\right) u_{w d}{ }^{2} ; \\
C_{w d y}\left(\beta_{w d}\right) u_{w d}{ }^{2} ; \\
C_{w d z}\left(\beta_{w d}\right) u_{w d}{ }^{2},
\end{array}\right.
\end{gathered}
$$

where $C_{c x}, C_{c y}$ and $C_{c z}$ are drag coefficients of current in surge, sway and yaw respectively, $u_{c}$ is the relative velocity between platform and current, and $\beta_{c}$ is the current direction defined in the body-fixed reference frame. $C_{w d x}, C_{w d y}$ and $C_{w d z}$ are drag coefficients of wind in surge, sway and yaw respectively, $u_{w d}$ is the relative velocity between platform and wind, and $\beta_{w d}$ is the wind direction defined in the body-fixed reference frame.

The second order wave force is in quadratic relationship to the wave height, and its vectors in surge, sway and yaw are formulated as:

$$
\tau_{\text {wave }}=\left\{\begin{array}{l}
2 \int_{0}^{\infty} S(w) C_{\text {wax }}\left(w, \beta_{\text {wave }}\right) d w \\
2 \int_{0}^{\infty} S(w) C_{\text {way }}\left(w, \beta_{\text {wave }}\right) d w \\
2 \int_{0}^{\infty} S(w) C_{w a z}\left(w, \beta_{\text {wave }}\right) d w
\end{array}\right.
$$

where $C_{w a x}, C_{w a y}$ and $C_{w a z}$ are the quadratic force transfer functions of second order wave force in surge, sway and yaw respectively, $w$ is circular frequency of wave, and $S(w)$ is the wave spectrum for a given environment.

The thruster force depends on the control system of marine platform. The linear quadratic gaussian controller is often used in the marine platform, and the relevant thruster force vector is expressed as [13]:

$$
\boldsymbol{\tau}_{\text {truster }}=-\boldsymbol{G} \boldsymbol{\eta},
$$

where $\boldsymbol{G}$ is control gain matrix.

The riser force vector can be calculated based on the top tension and angle of riser, which is formulated as: 


$$
\tau_{\text {riser }}=\left\{\begin{array}{c}
T_{\text {tension }} \sin \left(\theta_{r x}\right) ; \\
T_{\text {tension }} \sin \left(\theta_{r y}\right) ; \\
G_{r} I_{p} \frac{\theta_{r z}}{L},
\end{array}\right.
$$

where $T_{\text {tension }}$ is riser top tension, $\theta_{r x}, \theta_{r y}, \theta_{r z}$ are riser angles in surge, sway and yaw respectively, $G_{r}$ is shearing modulus of elasticity of riser, $I_{p}$ is polar moment of inertia of riser, and $L$ is riser length.

\subsection{Riser analysis equations}

The riser/wellhead/conductor system deforms laterally under the combined loads of wave, current and soil resistance. The dynamic analysis differential equation of riser is given as [14]:

$$
\begin{array}{r}
\frac{\partial^{2}}{\partial z^{2}}\left(E I_{r}(z) \frac{\partial^{2} x}{\partial z^{2}}\right)-\frac{\partial}{\partial z}\left(T_{r}(z) \frac{\partial x}{\partial z}\right)+ \\
+M_{r}(z) \frac{\partial^{2} x}{\partial t^{2}}=F(z, t),
\end{array}
$$

where $E$ is elastic modulus of riser; $I_{r}$ is the inertia moment of riser; $T$ is effective tension of riser; $M_{r}$ is the mass of riser per unit length, and $F$ is externally loads including marine environment loads and soil resistance force.

The marine environment loads per unit length on the riser above the mudline are determined by using Mori- son's equation:

$$
\begin{aligned}
F_{\text {sea }}(z, t) & =\frac{\pi}{4} \rho C_{M} D_{h}{ }^{2} \dot{u}_{w}-\frac{\pi}{4} \rho\left(C_{M}-1\right) D_{h}{ }^{2} \ddot{x}+ \\
& +\frac{1}{2} \rho D_{h} C_{D}\left(u_{w}+u_{c}-\dot{x}\right)\left|u_{w}+u_{c}-\dot{x}\right|,
\end{aligned}
$$

where $C_{D}$ is drag coefficient, $\rho$ is sea water density; $D_{h}$ is hydrodynamic diameter of riser; $C_{M}$ is inertia coefficient; $u_{w}$ is water particle velocity induced by wave; $\dot{u}_{w}$ is water particle acceleration induced by wave, and $u_{c}$ is water particle velocity induced by current.

The soil resistance force per unit length on the conductor under the mudline is expressed as [15]:

$$
F_{\text {soil }}(z, x)=p(z, x) D_{c}(z)
$$

where $p$ is foundation resistance force per unit area, and $D_{c}$ is external diameter of conductor.

Besides, the top of riser is under the influence of platform drive-off, and the specific drive-off motion should be calculated based on coupled dynamic analysis model of deepwater platform/riser system.

\subsection{Coupled analysis method}

Based on the established dynamic analysis model of deepwater platform and riser, a coupled dynamic analysis method for the drive-off of deepwater platform/riser system is proposed, as shown in Fig. 3.

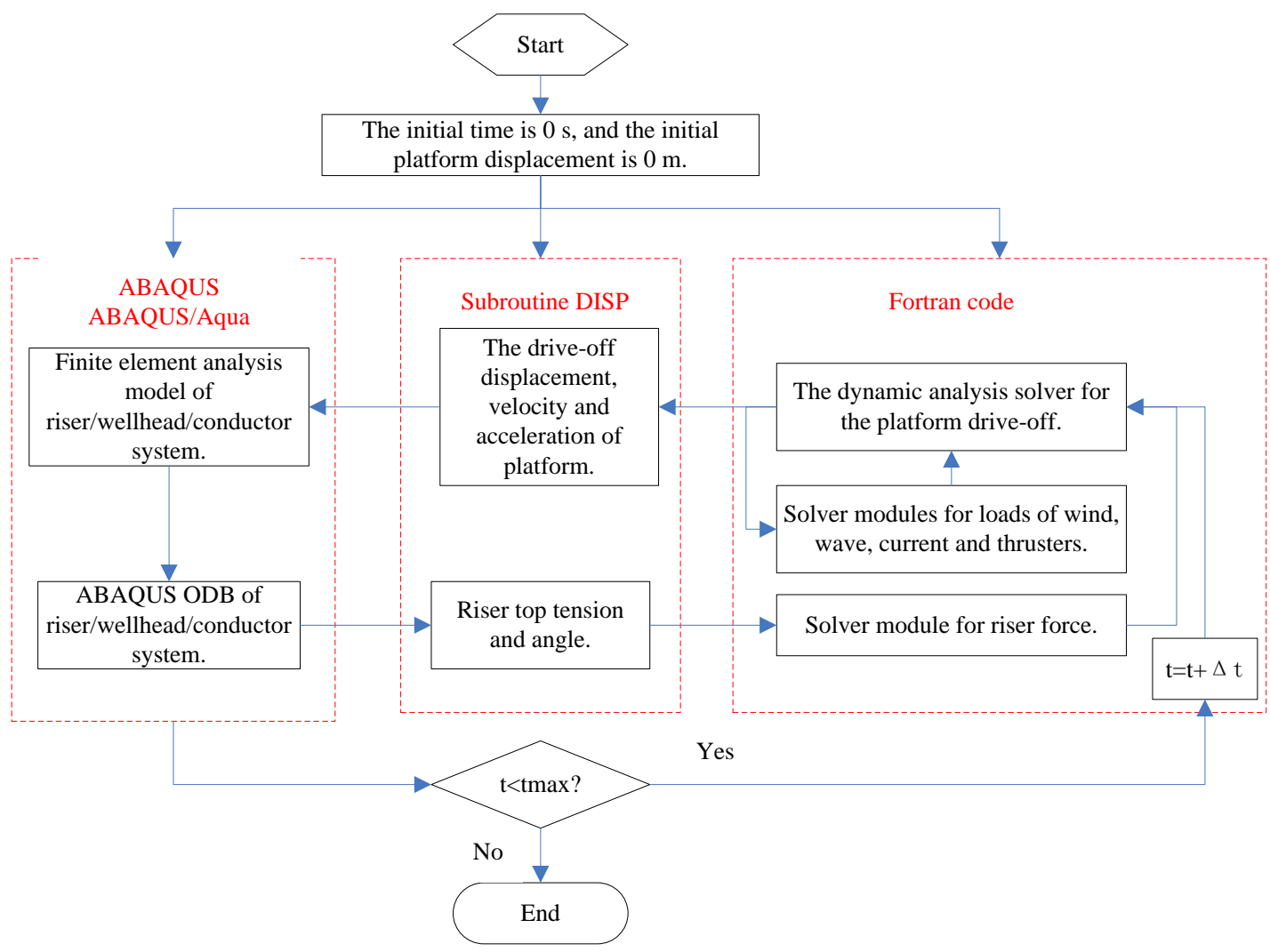

Fig. 3 Coupled analysis flow

The finite element analysis model of riser/wellhead/conductor system is built in ABAQUS. Pipe element is adopted to model the riser/wellhead/conductor system. The upper boundary of riser system starts from UFJ which is modeled by joint element with rotation stiffness. The lower boundary of riser system ends at conductor 
system and the soil resistance force on conductor is modeled by spring element [16]. Then, marine environment loads are applied on riser system. And the finite element model can be solved by ABAQUS marine engineering module ABAQUS/Aqua.

State space method is used to solve the drive-off motion equations of platform. The dynamic analysis solver for the platform drive-off is developed in FORTRAN language. And the relevant solver modules for loads of wind, wave, current, thruster and riser force are also developed, respectively. The parameter transfer and iterative calculation between riser analysis model and platform drive-off solver are carried out by means of ABAQUS user-defined subroutine DISP.

The combined calculation of the drive-off of deepwater platform/riser system is an iterative process. Firstly, the drive-off displacement, velocity and acceleration of platform are calculated based on the developed drive-off solver. The relevant motion parameters of platform are transferred to the riser analysis model for riser dynamic analysis, and to external load solver modules of platform for the latest loads calculation. Then the riser dynamic model is analyzed based on the transferred motion parameters of platform. And the riser top tension and angle are fed back to dynamic analysis solver of platform and the riser loads acting on the platform can be calculated. The next round of the drive-off calculation of platform/riser system can be carried out based on the latest ocean environment loads, thruster force and riser force. Finally, the dynamic drive-off analysis of deepwater platform/riser system can be completed through a series of iterative calculations.

\section{Results and discussions}

The parameters used for numerical simulation are: $m=4.08 \times 10^{7} \mathrm{~kg} ; X_{\dot{u}}=1.18 \times 10^{7} \mathrm{~kg} ; Y_{\dot{v}}=4.32 \times 10^{7} \mathrm{~kg} ;$ $I_{\mathrm{Z}}=1.19 \times 10^{11} \mathrm{~kg} \cdot \mathrm{m}^{2} ; N_{\dot{r}}=1.38 \times 10^{11} \mathrm{~kg} \cdot \mathrm{m}^{2} ; Y_{\dot{r}}=0 \mathrm{~kg} ;$ $N_{\dot{v}}=0 \mathrm{~kg} \cdot \mathrm{m}^{2} ; E=207 \mathrm{GPa} ; G_{r}=79 \mathrm{GPa} ; I_{r}=0.0012 \mathrm{~m}^{4}$; $I_{p}=0.0024 \mathrm{~m}^{4} ; T_{\text {tension }}=3.02 \mathrm{MN} ; L=1327 \mathrm{~m} ; M_{r}=280 \mathrm{~kg}$; $D_{h}=0.5334 \mathrm{~m} ; D_{c}=0.9144 \mathrm{~m} ; C_{D}=1.2 ; C_{M}=2$. The sea state of Beaufort level 6 is selected for the drive-off analysis. Wind velocity, wave height, wave period and surface current velocity are $13.8 \mathrm{~m} / \mathrm{s}, 3 \mathrm{~m}, 6.7 \mathrm{~s}$ and $0.5 \mathrm{~m} / \mathrm{s}$, respectively. And the directions of wind, wave and current are assumed to be the same. The platform is assumed to be driven $100 \mathrm{~m}$ away from subsea wellhead in horizontal direction due to the wrong information of reference system. The driving directions $0^{\circ}$ (along environment) and $180^{\circ}$ (against environment) are selected for the drive-off analysis respectively. The drive-off curves of deepwater platform are calculated, as shown in Fig. 4.

Fig. 4 shows the drive-off velocity of platform in the $0^{\circ}$ direction is greater than that in the $180^{\circ}$ direction, which is caused by the combined force of thruster force and environment loads. When the platform is driven off in the $0^{\circ}$ direction, the thruster force direction is the same with environment load direction, and the combined force is great. While when the platform is driven off in the $180^{\circ}$ direction, the thruster force direction is the opposite of environment load direction, and the combined force is less than that in the $0^{\circ}$ direction. So the platform reaches the target position in the $0^{\circ}$ direction earlier than that in the $180^{\circ}$ direction. During the iterative calculations of platform and riser system, the drive-off movement of platform is applied to riser analysis model for the top boundary condition and the riser displacements under different drive-off time are calculated, as shown in Fig. 5. In reverse, the riser system applied a reaction force on platform as shown in Fig. 6.

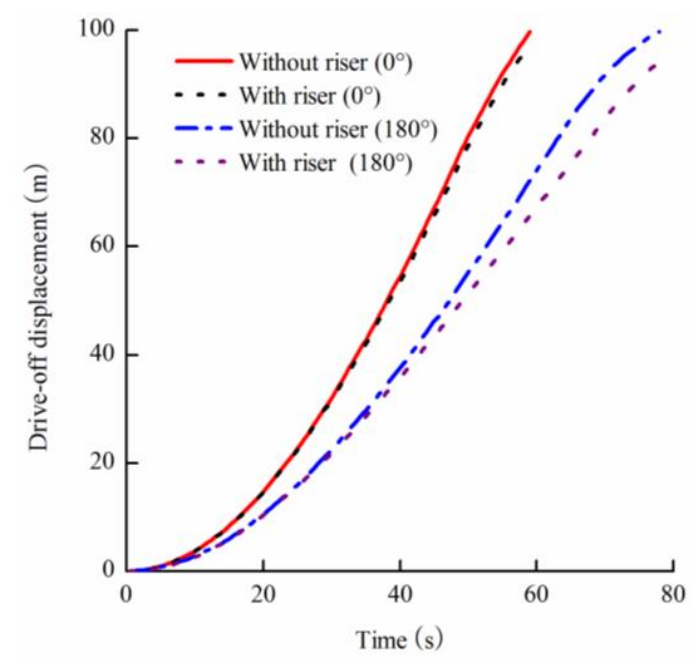

Fig. 4 Drive-off curves of deepwater platform

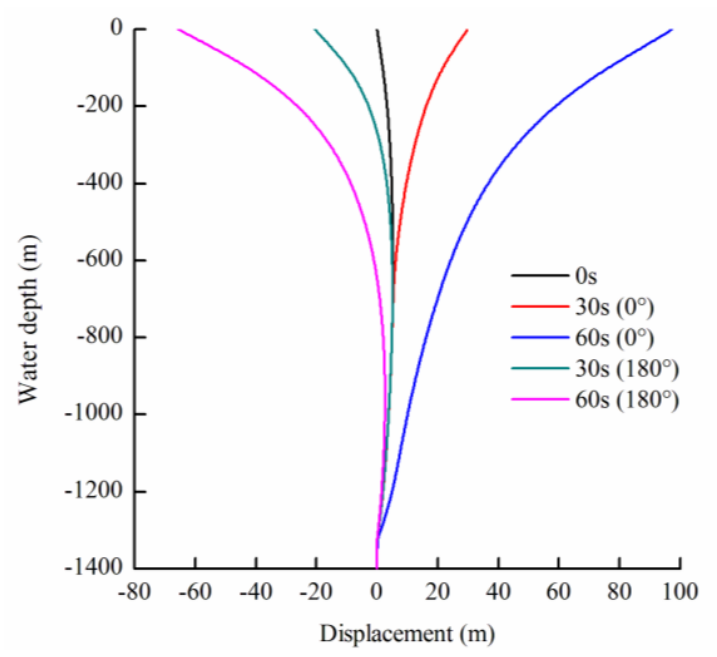

Fig. 5 Displacements of deepwater riser during drive-off

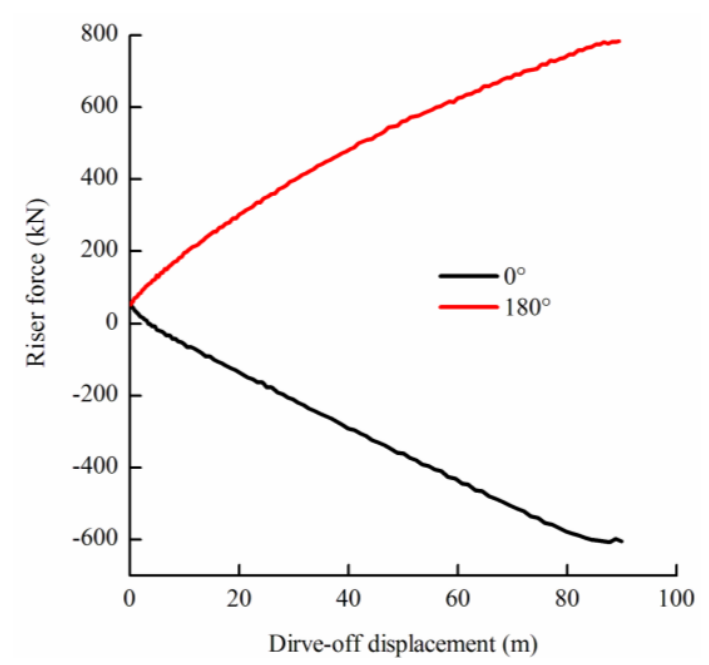

Fig. 6 Riser force acting on platform during drive-off 
From Fig. 5, it can be seen that when the platform drives off in the $0^{\circ}$ direction, the deepwater riser deflects along the environment direction under the current and wave loads in the initial drive-off stage. So the riser force acting on platform is also positive according to the formula (9), and plays a driving role in the platform drive-off in the initial drive-off stage, as shown in Fig. 6. As the drive-off displacement of platform increases, the riser top angle changes from positive to negative gradually, and the riser force acting on platform begins to inhibit the platform drive-off. Overall, the riser force acting on platform plays an inhibiting role in the platform drive-off. So the drive-off displacement of platform with riser is smaller than that without riser when the platform drives off in the $0^{\circ}$ direction, as shown in Fig. 4. When the platform drives off in the $180^{\circ}$ direction, the direction of riser force acting on platform is always against with drive-off direction, as shown in Fig. 5. And the absolute value of riser force is bigger than that in $0^{\circ}$ direction, as shown in Fig. 6 . So the drive-off displacement of platform with riser is obviously smaller than that without riser, as shown in Fig. 4.

To further understand the dynamic characteristics of riser comprehensively, key parameters including UFJ angle, LFJ angle, telescopic joint stroke, conductor stress and wellhead bending moment are often extracted [17]. The calculated key parameters are extracted from the drive-off analysis result when the platform drives off in the $0^{\circ}$ direction. The values of key parameters are normalized by the way of expression (calculated values / critical values), as shown in Fig. 7. The critical values of UFJ angle, LFJ angle, telescopic joint stroke, riser strength, conductor strength and wellhead bending moment are $12^{\circ}, 6^{\circ}, 9.905$ $\mathrm{m}, 386 \mathrm{MPa}$ and $7.8 \mathrm{MN} \cdot \mathrm{m}$, respectively.

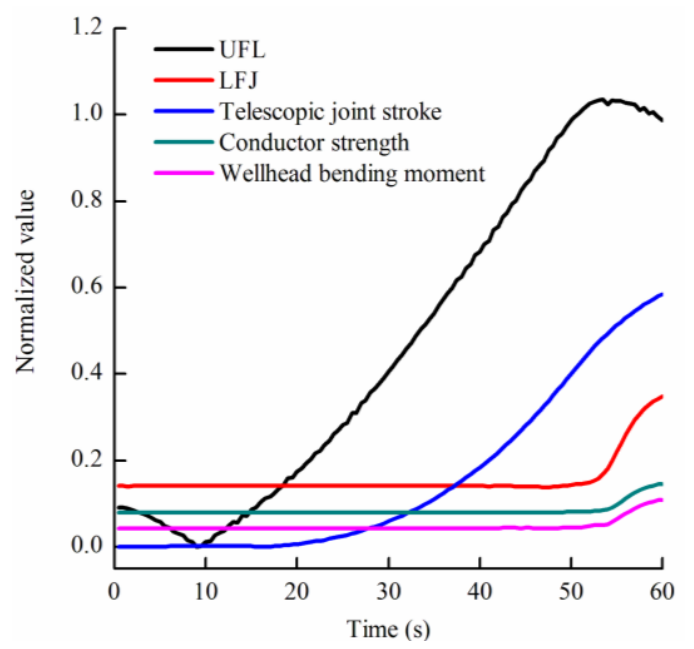

Fig. 7 Response of key parameters of deepwater riser

As shown in Fig. 7, the response speeds of key parameters during the platform drive-off are different from each other. Transient response speeds of LFJ angle, conductor stress and wellhead bending moment are obviously low compared with that of UFJ angle and telescopic joint stroke. The main reason is that riser's inertial effects are taken into account in the transient drive-off analysis of deepwater platform/riser system. The top of riser experiences motions much earlier than the bottom during the platform drive-off. The bottom LFJ angle, conductor stress and wellhead bending moment are essentially constant within a period of hysteresis time. Besides, the UFJ angle of deepwater riser increases quickly and reaches the critical value firstly during the platform drive-off. The UFJ angle reaches up to $12^{\circ}$ when the drive-off time is $50 \mathrm{~s}$. The bottom disconnect of riser should be completed before this time, or the riser may be damaged.

\section{Conclusions}

1. An extended finite element method for the coupled drive-off of deepwater platform/riser is proposed within the finite element software ABAQUS. The dynamic analysis model of deepwater riser system is established in ABAQUS software, and the drive-off dynamic solver of deepwater platform is developed in FORTRAN language. The parameter transfer and iterative calculation between the riser analysis model and the platform drive-off solver are carried out by ABAQUS subroutine DISP.

2. When the platform drives off along the ocean environment, the riser force acting on platform plays a driving role in the platform drive-off in the initial drive-off stage. As the drive-off displacement of platform increases, the riser force acting on platform begins to inhibit the platform drive-off.

3. When the platform drives off against the ocean environment, the riser force acting on platform always plays an inhibiting role in the platform drive-off. And the drive-off displacement of platform with riser is obviously smaller than that without riser.

4. The top of riser experiences motions much earlier than the bottom during the platform drive-off. The bottom LFJ angle, conductor stress and wellhead bending moment are essentially constant within a period of hysteresis time.

\section{Acknowledgements}

The authors wish to acknowledge the financial support of the National Program on Key Basic Research Project (2015CB251203), Natural Science Foundation of Shandong Province (ZR2014EL018), China Postdoctoral Science Foundation (2015M570621) and China University of Petroleum Graduate Student Innovation Project (YCX2015040).

\section{References}

1. Bakken, B.I.; Olsen, T. 2001. Risk associated with drive-off/drive-off when drilling on DP, Dynamic Positioning Conference, Houston, Texas, USA.

2. Chen, H.B.; Moan, T.; Verhoeven, H. 2008. Safety of dynamic positioning operations on mobile offshore drilling units, Reliability Engineering \& System Safety 93: 1072-1090. http://dx.doi.org/10.1016/j.ress.2007.04.003.

3. Chen, H.B.; Moan, T.; Verhoeven, H. 2009. Effect of DGPS failures on dynamic positioning of mobile drilling units in the North Sea, Accident Analysis and Prevention 41: 1164-1171. http://dx.doi.org/10.1016/j.aap.2008.06.010.

4. Shaughnessy, J.M.; Armagost, W.K.; Herrmann, R.P.; Cleaver, M.A. 1999. Problems of ultradeepwater drilling, SPE/IADC Drilling Conference, Amsterdam, Holland. http://dx.doi.org/10.2118/52782-MS. 
5. Hansen, E.O.S.; Royce, R. 2011. DP dependability, Dynamic Positioning Conference, Houston, Texas, USA.

6. Morishita, H.M.; Souza, C.E.S. 2014. Modified observer backstepping controller for a dynamic positioning system, Control Engineering Practice 33: 105-114. http://dx.doi.org/10.1016/j.conengprac.2014.08.012.

7. Sørensen, A.J. 2011. A survey of dynamic positioning control systems, Annual Reviews in Control 35: 123136. http://dx.doi.org/10.1016/j.arcontrol.2011.03.008.

8. Ambrose, B.; Keener, C.; Farr, D. 2003. Deepwater dynamically positioned drillships - how shallow can they go?, Offshore Technology Conference, Houston, Texas, USA. http://dx.doi.org/10.4043/15236-MS.

9. Bhalla, K.; Cao, Y.S. 2001. Watch circle assessment of drilling risers during a drive-off and drive-off event of a dynamically positioned vessel, Dynamic Positioning Conference, Houston, Texas, USA.

10. Gjerde, T.; Chen, H. 2014. Probabilistic red limit study for mobile offshore drilling units, Proceedings of the ASME 33rd International Conference on Ocean, Offshore and Arctic Engineering, San Francisco, California, USA. http://dx.doi.org/10.1115/OMAE2014-24614.

11. Liu, X.Q.; Chen, G.M.; Chang, Y.J.; Liu, K.; Zhang, L.; Xu, L.B. 2013. Analyses and countermeasures of deepwater drilling riser grounding accident under typhoon conditions, Petroleum Exploration and Development 40(6): 738-742.

http://dx.doi.org/10.1016/S1876-3804(13)60106-8.

12. Leira, B.J.; Sørensen, A.J.; Larsen, C. 2004. A reliability-based control algorithm for dynamic positioning of floating vessels, Structural Safety 26: 1-28. http://dx.doi.org/10.1016/S0167-4730(03)00018-3.

13. Sørensen, A.J.; Sagatun, S.I.; Fossen, T.I. 1996. Design of a dynamic positioning system using modelbased control, Control Eng. Practice 4(3): 359-368. http://dx.doi.org/10.1016/0967-0661(96)00013-5.

14. Khan, R.A.; Ahmad, S. 2007. Dynamic response and fatigue reliability analysis of marine riser under random loads, Proceedings of the 26th International Conference on Ocean, Offshore and Arctic Engineering, San Diego, California, USA.

http://dx.doi.org/10.1115/OMAE2007-29235.

15. Recommended practice for planning, design and constructing fixed offshore platforms-Working Stress Design, API RP 2A-WSD.

16. Yan, W.; Chen, Z.J.;, Deng, J.G.; Zhu, H.Y.; Deng, F.C.; Liu, Z.L. 2015. Numerical method for subsea wellhead stability analysis in deepwater drilling, Ocean Engineering 98: 50-56.

http://dx.doi.org/10.1016/j.oceaneng.2015.02.007.

17. Robinson, E. 1997. Drilling fundamentals-DP operations-drilling with riser, Dynamic Positioning Conference, Houston.

Xiuquan Liu, Guoming Chen, Jingqi Ji, Jingjie Fu

\section{COUPLED DYNAMIC ANALYSIS ON THE DRIVE-OFF OF DEEPWATER PLATFORM/RISER SYSTEM}

S u m m a r y

In this paper, a coupled dynamic analysis method on the drive-off of deepwater platform/riser system is proposed. The dynamic analysis model of deepwater riser is established in ABAQUS software, and the drive-off dynamic solver of deepwater platform is developed in FORTRAN language. The parameter transfer and iterative calculation between riser analysis model and platform drive-off solver are carried out by ABAQUS subroutine DISP. In an application case, the drive-off dynamics and the coupling effect of deepwater platform and riser system are discussed comprehensively. The results show that the coupling effect between the deepwater platform and riser is obvious. And the response hysteresis effect in bottom of riser during the platform drive-off is found.

Keywords: deepwater, platform, riser, drive-off, coupled dynamics.

Received December 05, 2015 Accepted April 14, 2017 